\title{
Combined ultrasound and electric field stimulation prompts an immediate response in stalled chronic wounds
}

This article was published in the following Dove Press journal:

Chronic Wound Care Management and Research

23 September 2016

Number of times this article has been viewed

\author{
Fabrizia Toscanella' \\ Jonathan Rosenblum² \\ Sean Rosenblum ${ }^{3}$ \\ 'Casa Di Cura Villa Tiberia, Rome, \\ Italy; ${ }^{2}$ Shaare Zedek Medical Center, \\ Jerusalem, Israel; ${ }^{3}$ rivate Practice, \\ Lodi, NJ, USA
}

\begin{abstract}
The authors evaluated a new technology - combined ultrasound and electric field stimulation (CUSEFS) - on the immediate effect on stagnant chronic wounds. We took 18 patients with chronic wounds that had not responded to therapy in the last month and added CUSEFS to their treatment regimen. Using digital planimetry to evaluate the wounds, we looked at the results after 1 week and two treatments. All wounds responded to therapy. A total of 13 out of 18 showed a reduction in surface area during the week of treatment. Of the five that did not show a response by measured area, there was a positive change in wound volume and quality of tissue in the base. The authors feel that after such a start, CUSEFS deserves further evaluation as an addition to the wound-care therapist's armamentarium.
\end{abstract}

Keywords: ultrasound, electric stimulation, therapies

\section{Introduction}

A chronic wound is one where the orderly biological progression to healing has been disrupted and healing delayed. ${ }^{1}$ Chronic wounds affect more than 6 million Americans, with an annual cost estimated at $\$ 25$ billion. $^{2}$ These wounds frequently manifest in the setting of diabetes mellitus and are associated with diminished new bloodvessel formation (neovascularization), leading to an impaired wound-healing response. ${ }^{3}$

Advanced wound-care therapy continues to evolve, with a growing number and type of products now available on the market. In recent years, physical and mechanical modalities for the treatment of chronic wounds have also begun to play an important role. Ultrasound (US) therapy and therapies implementing electric stimulation have been used in the wound-care armamentarium for over 100 years.

Therapeutic US has gained in popularity as a modality with significant efficacy in the treatment of chronic wounds. ${ }^{4}$ Several mechanisms for the efficacy of therapeutic US have been proposed. These include reduction of edema, ${ }^{5}$ inhibition of bacterial colonization, ${ }^{6}$ stimulation of neovascularization ${ }^{7}$ and subsequent tissue formation, ${ }^{5,7}$ leukocyte adhesion to endothelial cells, ${ }^{8}$ and macrophage stimulation of fibroblast proliferation. ${ }^{9}$

Electric stimulation has been applied in various types of electrical fields, with various currents and intensities for the treatment of soft-tissue and skin injury for over 100 years. ${ }^{10}$ Some of the effects of electric stimulation are release of growth factors, ${ }^{11}$ increasing tissue oxygenation by changing vascular permeability. ${ }^{12}$ Also, keratinocytes and fibroblasts
Correspondence: Jonathan Rosenblum Shaare Zedek Medical Center, Shmu'el Bait St 12, Jerusalem, 9103102, Israel Email diabfootman@gmail.com 
migrate to a pole in the electric field, ${ }^{13}$ as do some immune cells, eg, lymphocytes. ${ }^{14}$ The authors evaluated a device using combined US and electric field stimulation (CUSEFS) therapies for their combined effect on wound healing.

\section{Materials and methods}

Ethical approval was obtained from the Institutional Review Board of Shaarei Zedek Medical Center. Written informed consent was obtained from the patients for inclusion in this study, publication of this paper, and the accompanying images. A total of 18 wounds were evaluated for this study. All wounds were vascular in nature, and had been present for a minimum of 2 months. Table 1 demonstrates the demographic data of the wounds included in the study. As a further inclusion criterion, the wounds had exhibited no change in the 30 days preceding enrollment in the study. Patients continued with the same treatment they had been using during the 2 weeks prior to enrollment in the study, and the only change made to their treatment plan was the addition of CUSEFS twice weekly.

CUSEFS was applied using the BRH-A2 device (BRH Medical, Jerusalem, Israel) according to the manufacturer's protocol. Patients were administered 2 minutes of electric stimulation and then 11 minutes of CUSEFS and a further 2 minutes of electric stimulation. Patients were then dressed with any wound-care products they had been using prior to the study. Patients were invited back for follow-up treatment after 3 or 4 days and were enrolled in twice-weekly treatments for a minimum of 4 weeks.

Wound measurement was performed with the digital planimetry system integrated in the BRH-A2 CUSEFS system. Measurement was performed by taking a digital photograph of the wound with a ruler for calibration. The wound edges were then traced by a single, independent reviewer, in order to reduce measurement bias. The measurement system calculated the area of the wound. Although not part of the study and not evaluated, patients continued using CUSEFS in addition to their current wound-care protocol twice weekly.

\section{Results}

Table 1 shows the results of the study. Thirteen of the 18 wounds exhibited reduction in surface area during the first week of treatment. The average closure was $10.8 \%$. The average closure rate was $20.97 \%$ for the wounds that showed reduction in size. Figures 1 and 2 are representative of wounds that showed a reduction in size. Of the five that did not show a reduction in area, there was however a significant reduction in wound volume and depth. Figures 3 and 4 are representative of the wounds that did not show a reduction in area. The quality of the tissue within the wound bed was significantly modified, showing a more robust granular appearance almost immediately after treatment. The wound edge, which in almost all cases had a pearly, folded-over look prior to treatment, had a much flatter, open-looking wound edge after treatment. There was a slight increase in drainage from the wounds, but it was serous in nature, and there were no signs of infection.

Upon questioning, patients related that they felt a slight decrease in pain related to the wound. Some of the patients noted that they felt some discomfort at the beginning of the treatment, but it was understood this feeling was related to the motion of the US head, and the discomfort subsided almost immediately.

Table I Patient demographics and results

\begin{tabular}{|c|c|c|c|c|c|c|}
\hline $\begin{array}{l}\text { Patient } \\
\text { number }\end{array}$ & $\begin{array}{l}\text { Patient age, } \\
\text { years }\end{array}$ & $\begin{array}{l}\text { Wound duration, } \\
\text { months }\end{array}$ & Sex & $\begin{array}{l}\text { Size at } \\
\text { presentation, } \mathrm{cm}^{2}\end{array}$ & $\begin{array}{l}\text { Size after two } \\
\text { treatments, } \mathrm{cm}^{2}\end{array}$ & $\%$ change \\
\hline I & 74 & 24 & Female & $|5.5|$ & 11.41 & 26 \\
\hline 2 & 96 & 4 & Female & 1.85 & 1.71 & 7 \\
\hline 3 & 69 & 36 & Male & 2.49 & 2.47 & 0.8 \\
\hline 4 & 69 & 36 & Male & 1.66 & 1.56 & 6 \\
\hline 5 & 55 & 4 & Female & 35.84 & 30.83 & 14 \\
\hline 6 & 84 & 60 & Female & 4.25 & 4.63 & -9 \\
\hline 7 & 84 & 60 & Male & 1.31 & 1.08 & 17.5 \\
\hline 8 & 51 & 6 & Male & 5.95 & 5.68 & 4.5 \\
\hline 9 & 51 & 6 & Male & 2.91 & 3.49 & -20 \\
\hline 10 & 78 & 2 & Male & 12.62 & 3.41 & 73 \\
\hline II & 91 & 36 & Male & 1.09 & 1.47 & -35 \\
\hline 12 & 67 & 2 & Female & 1.64 & 0.86 & 48 \\
\hline 13 & 49 & 36 & Male & 25.75 & 25 & 3 \\
\hline 14 & 34 & 60 & Female & 3.34 & 3.4 & -2 \\
\hline 15 & 34 & 60 & Female & 3.95 & 1.64 & 58 \\
\hline 16 & 65 & 36 & Female & 75.53 & 74.44 & 1.4 \\
\hline 17 & 34 & 13 & Male & 3.05 & 3.37 & -10 \\
\hline 18 & 59 & 48 & Male & 15.36 & 13.52 & 12 \\
\hline Average & 63 & 29 & & 11.9 & 10.55 & 10.8 \\
\hline
\end{tabular}




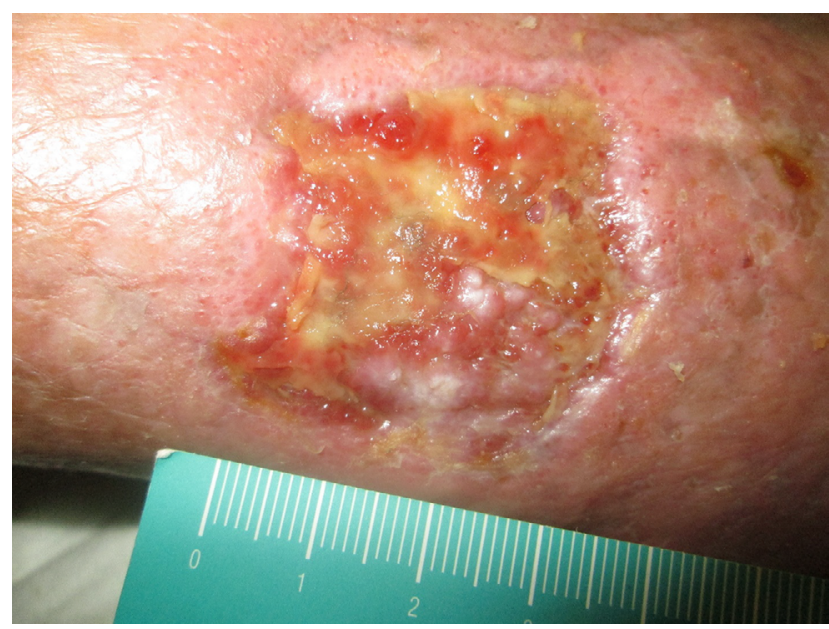

Figure I Before treatment with combined ultrasound and electric field stimulation.

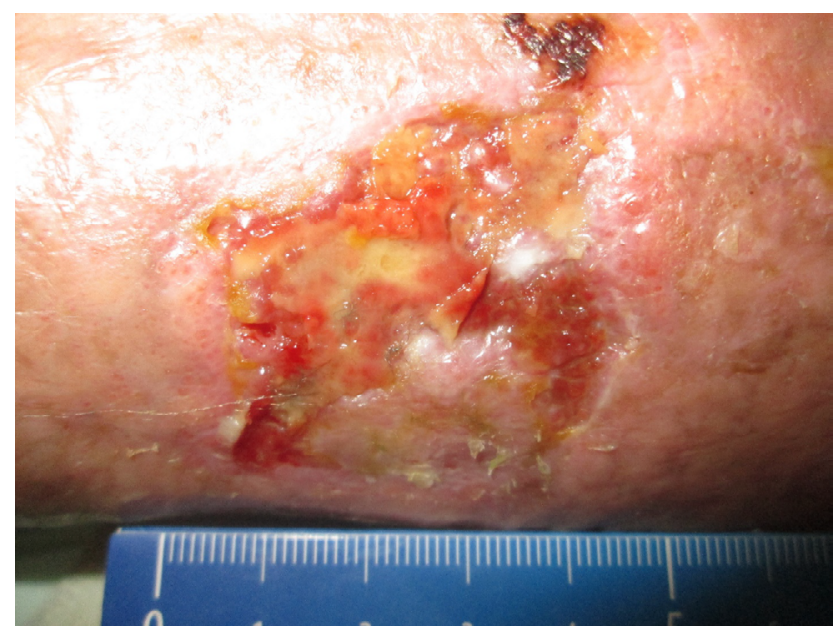

Figure 2 After treatment with combined ultrasound and electric field stimulation, with decreased surface area.

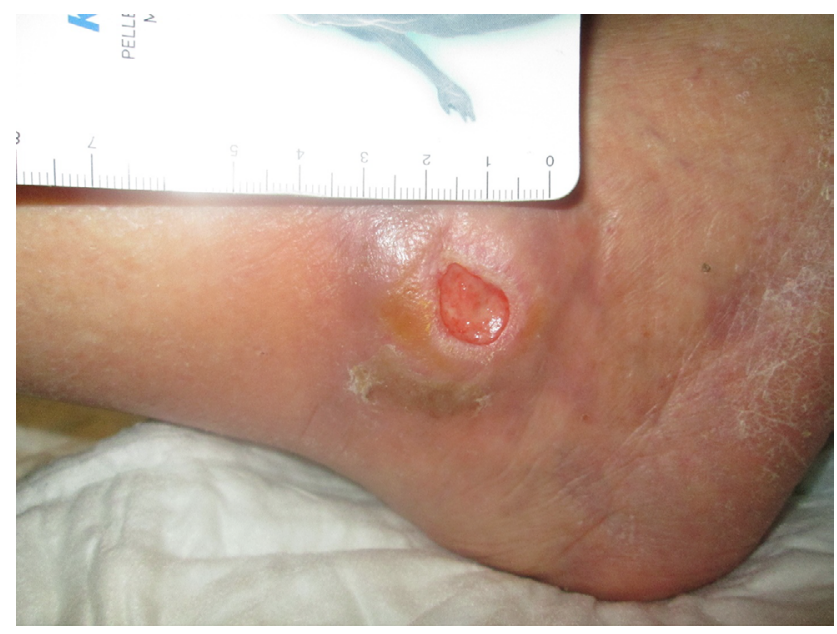

Figure 3 Before treatment with combined ultrasound and electric field stimulation.

\section{Discussion}

While much has been written and studied about the effect of US and electric stimulation and the effect of these modalities on wound healing, most has been directed at overall and

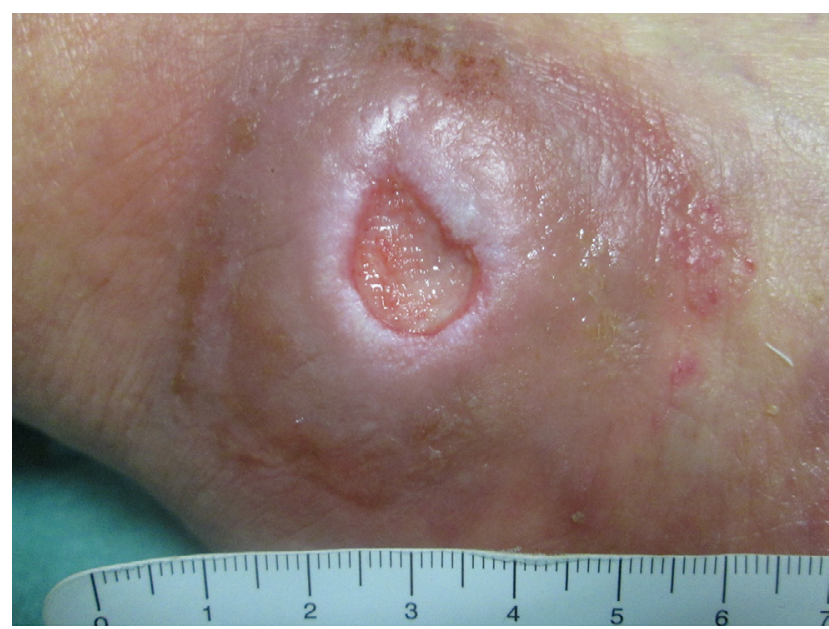

Figure 4 After I week of treatment: no reduction in area, but note the positive change in the wound.

long-term changes. Little has been said about the immediate effect, and how these therapies may produce an effect in the wound after only one or two treatments.

In contradistinction to drug therapies, physical modalities do not necessarily have a dosage threshold that needs to be overcome in order to produce a result. The simplest example of that would be the body's inflammatory response to a physical insult, ie, a slap will generate an erythematous flush. When US or electric stimulation is applied to heal a wound, the physical effect is instantaneous. Changes to the cells are forced by the surrounding conditions. ${ }^{15,16}$ While these effects might take a while to be effective on a subcellular level, at a gross level they occur from the commencement of therapy.

The components of US and EFS are complementary. Many of their cellular and subcellular effects are similar, and the mixture of the two has an additive effect. The micromovement generated by the modalities causes an immediate effect, with the two distinct wave types having a cellular affect both individually and combined.

This study looked at the initial and immediate response to CUSEFS by wounds that had been stagnant for a minimum of 30 days. This was a pilot study, so the sample size was small and the study design open, both of which should be addressed in future evaluation of this device. The investigators are continuing to evaluate the device on these patients for wound closure, but chose an interim evaluation of the device specifically because of the stagnant nature of the wounds and the initial reaction of the wounds to treatment with CUSEFS. In the authors' experience, most modalities for wound therapy, especially physical modalities, take some time to begin affecting the wound and its environment and effecting closure. The authors found it very encouraging that there was such an initial response, 
and found that very promising for a continued effect on wound closure. Future research should compare other devices directly for initial as well as continued efficacy. Randomized controlled trials should be conducted looking at both parameters, and should focus on the wound both grossly and microscopically.

\section{Conclusion}

Although this was an open-label study, and the authors recognize the need for an RCT, the results certainly support the statement that CUSEFS has an immediate effect on wound healing in stalled chronic wounds. Continued use of CUSEFS helps to heal these wounds in a much timelier fashion.

\section{Disclosure}

The authors report no conflicts of interest in this work.

\section{References}

1. Lazarus GS, Cooper DM, Knighton DR, et al. Definitions and guidelines for assessment of wounds and evaluation of healing. Arch Dermatol. 1994;130:489-493.

2. Sen CK, Gordillo GM, Roy S, et al. Human skin wounds: a major and snowballing threat to public health and the economy. Wound Repair Regen. 2009; 17:763-771.

3. Brem H, Tomic-Canic M. Cellular and molecular basis of wound healing in diabetes. J Clin Invest. 2007;117:1219-1222.
4. Johannsen F, Gam AN, Karlsmark T. Ultrasound therapy in chronic leg ulceration: a meta-analysis. Wound Repair Regen. 1998;6:121-126.

5. Houghton PE, Campbell KE. Choosing an adjunctive therapy for the treatment of chronic wounds. Ostomy Wound Manage. 1999;45:43-52.

6. Seth AK, Nguyen KT, Geringer MR, et al. Noncontact, low-frequency ultrasound as an effective therapy against Pseudomonas aeruginosainfected biofilm wounds. Wound Repair Regen. 2013;21:266-274.

7. Young SR, Dyson M. The effect of therapeutic ultrasound on angiogenesis. Ultrasound Med Biol. 1990;16:261-269.

8. Maxwell L, Collecutt T, Gledhill M, Sharma S, Edgar S, Gavin JB. The augmentation of leucocyte adhesion to endothelium by therapeutic ultrasound. Ultrasound Med Biol. 1994;20:383-390.

9. Young SR, Dyson M. Macrophage responsiveness to therapeutic ultrasound. Ultrasound Med Biol. 1990;16:809-816.

10. Reid B, Zhao M. The electrical response to injury: molecular mechanisms and wound healing. Adv Wound Care (New Rochelle). 2014;3: 184-201.

11. Callaghan MJ, Chang EI, Seiser N, et al. Pulsed electromagnetic fields accelerate normal and diabetic wound healing by increasing endogenous FGF-2 release. Plast Reconstr Surg. 2008;121:130-141.

12. Connolly DT. Vascular permeability factor: a unique regulator of blood vessel function. J Cell Biochem. 1991;47:219-223.

13. Nishimura KY, Isseroff RR, Nuccitelli R. Human keratinocytes migrate to the negative pole in direct current electric fields comparable to those measured in mammalian wounds. J Cell Sci. 1996;109:199-207.

14. Li J, Nandagopal S, Wu D, et al. Activated T lymphocytes migrate toward the cathode of DC electric fields in microfluidic devices. Lab Chip. 2011;11:1298-1304.

15. Zhang H, Landmann F, Zahreddine H, Rodriguez D, Koch M, Labouesse M. A tension-induced mechanotransduction pathway promotes epithelial morphogenesis. Nature. 2011;471:99-103.

16. Lancerotto L, Bayer LR, Orgill DP. Mechanisms of action of microdeformational wound therapy. Semin Cell Dev Biol. 2012;23:987-992.
Chronic Wound Care Management and Research

\section{Publish your work in this journal}

Chronic Wound Care Management and Research is an international, peer reviewed, open access, online journal publishing original research, reviews, editorials, and commentaries on the causes and management of chronic wounds and the major issues related to chronic wound management. Topics also include chronic wounds as comorbidities to other

\section{Dovepress}

conditions, patient adherence to therapy, and the economic burden of chronic wounds. The manuscript management system is completely online and includes a very quick and fair peer review system, which is all easy to use. Visit http://www.dovepress.com/testimonials.php to read real quotes from published authors. 